\title{
KESEMBUHAN, PENEBUSAN, DAN KEBAIKAN ALLAH DALAM TEOLOGI PENTAKOSTAL ${ }^{1}$
}

\author{
MINGGUS MINARTO PRANOTO²
}

\begin{abstract}
This paper is about to criticize the Pentecostal theology about the healing. The theology believe that the miracle of healing can happen because Jesus died on the cross. He was able to heal all sicknesses and to free people from the shackles of the devil. Furthermore, the concept of God is a good God also used to refer to the belief that God has a strong desire to heal. But in reality, many Christians experience sickness is not healed. So the doctrine of the Pentecostal healing actually makes conflicted for people who have never experienced the healing of sickness, although he has been obedient and trust in the Lord. The author tries to reconstruct the Pentecostal theology of healing that could accommodate such a struggle. At the end of writing the author makes a conclusion that in sickness and suffering severe, the work of the Holy Spirit as the agent of transformative Suffering can not be separated from his work as the agent of the transformative life. The Holy Spirit as the agent of transformative

Suffering can wear sickness and suffering experienced by believers to proclaim the work of his reform, which is a new birth. The new birth here interpreted as the transformation of
\end{abstract}

1 Arti Pentakostal(kata sifat) atau Pentakosta (kata benda) mencakup juga untuk gerakan seperti Pentakosta baru, Karismatik, Karismatik Baru yang rata-rata pada umumnya mempunyai konsep yang kurang lebih sama tentang mujizat kesembuhan. Oleh karena itu dalam tulisan ini hanya disebut teologi Pentakostal saja (istilah Indonesia Pentakosta disebut Pantekosa). Aliran Pentakostal telah menampilkan "multi wajah" dalam aliran-aliran di atas yang saling tumpang tindih sekarang ini. Pdt.Minggus Minarto Pranoto, M.Th. merupakan dosen STT Abdiel. 


\section{the Holy Spirit in their lives so that their lives can sincerely declare lives according to the values of the Kingdom of God which contains joy, faithfulness, patience, love, truth, peace.}

These values are stronger than mere physical healing function experienced by a person.

Keyword: Theology, Pentacostal, Healing, Suffering, Sickness.

\section{PENDAHULUAN}

$\mathrm{T}_{\mathrm{t}}^{\mathrm{i}}$ irto $^{3}$ mengalami penyakit Spinocerebellar Ataxia (SCA) ${ }^{4}$ ketika ia berumur 40 tahun. Paman dan Ibunya meninggal pada usia sekitar 50 dan 60-an tahun dengan penyakit yang sama dengannya. Rupanya Tirto mengidap penyakit ini karena warisan genetika melalui garis keturunan keluarganya. Sebelum sakit, ia pemuda yang enerjik dan cukup berhasil usahanya berdagang karpet dan jual beli emas batangan. Ia punya cita-cita yang besar agar usahanya lebih berkembang. Selain itu ia juga mempunyai keinginan untuk meminang kekasihnya dalam waktu dekat. Tetapi semenjak ia mengalami penyakit itu, keluarga kekasihnya menolak keras rencana tersebut. Mereka tidak jadi menikah, namun kekasihnya tetap setia sampai sekarang menemani Tirto dalam kondisinya yang semakin lemah.

Suatu ketika ada tim visitasi gereja yang mengunjungi dia. Mereka mengatakan kepadanya bahwa semua penyakit dapat "dipatahkan dan diusir" di dalam nama Yesus sebagai penyembuh yang ajaib dan penebus dosa-dosa manusia. Mereka juga menekankan bahwa Allah itu baik dan Dia berkuasa menyingkirkan segala macam penyakit melalui kuasa Roh Kudus-Nya. Sebagaimana Gereja Pentakosta pada umumnya, gereja tempat Tirto beribadah cenderung memandang bahwa semua penyakit bukan berasal dari pekerjaan Allah tetapi berasal dari kuasa-kuasa jahat dan setan (evil forces and the devil) dan

3 Bukan nama sebenarnya.

4 Ada berbagai macam penyakit Ataxia seperti Ataxia telangiectasia, Episodic Ataxia, dan Friedreich's Ataxia. Penyakit yang diderita Tirto adalah Spinocerebellar Ataxia. Ahli medis Corrine O'Sullivan Smith dan kawan-kawan mendefinisikan Spinocerebellar Ataxia sebagai berikut: "Ataxia is a symptom, not a specific disease or diagnosis. Ataxia means poor coordination of movement. The term ataxia is most often used to describe walking that is uncoordinated and unsteady. Ataxia can affect coordination of fingers, hands, arms, speech (dysarthria) and eye movements (nystagmus)." Lihat https://www.ataxia.org/pdf/SCA-Making_an_Informed_Choice_About_Genetic_Testing.pdf diakses pada tanggal 10 Maret 2016. Smith juga mengatakan bahwa penyakit ini bisa berasal dari faktor warisan genetika orangtua (hereditary) dan bukan dari warisan genetika (Acquired ataxia). 
dosa - entah dari dirinya sendiri atau dosa orangtuanya yang mendatangkan kutuk -. Meskipun demikian perlu diberi catatan bahwa orang-orang Pentakosta sekarang ini mulai lebih terbuka dan menganggap bahwa penyakit juga dapat berasal dari kuman, virus, kelemahan genetika, dan kebiasaan hidup yang tidak sehat. Mereka tidak menolak biomedis (biomedicine), tetapi mereka tetap melihat kesembuhan ilahi-sebagaimana Ian Andrews katakan-“. . . as clearly more pure and powerful."5 Tirto sendiri dapat dikategorikan termasuk orang-orang Pentakosta masa kini karena ia beberapa kali pergi ke rumah sakit ternama di kota Semarang tempat ia tinggal dan bahkan ia pernah pergi ke Penang, Malaysia untuk menjalani terapi pengobatan. Ia mengkomsumsi obat secara teratur baik itu obat-obatan herbal maupun obat-obatan medis dari para dokter.

Tirto mendengar dari teologi tim visitasi bahwa penyebab sakit yang dideritanya adalah karena dosa keturunan dari orangtuanya, terutama dari garis keturunan Ibunya. Menurut tim visitasi dosa keturunan itu harus "dicabut dan dihancurkan" dalam kuasa penebusan Yesus. Dalam keadaan sakit yang dideritanya dan kesembuhan yang tidak kunjung sembuh melalui cara-cara medis, pada mulanya ia begitu mempercayai keyakinan teologis yang disampaikan oleh tim visitasi tersebut dan ia berdoa sungguh-sungguh agar kutuk dosa itu dilepaskan dari kehidupannya melalui mempercayai penebusan Yesus. Ia telah sekian lama berserah dan percaya bahwa kutuk itu pasti akan dilepaskan dari hidupnya tetapi fakta yang ada adalah mujizat tidak menghampirinya. Sebagai tambahan, ia pernah diundang di kebaktian kebangunan rohani di gereja tempat ia dan kekasihnya beribadah sebelum sakit. Saat altar call ia diundang maju oleh pembicara yang mempunyai karunia kesembuhan. Saat maju, ia diminta untuk bernazar oleh pembicara tersebut agar menerima kesembuhan. Ia dengan penuh iman mengucapkan nazarnya dan percaya sepenuhnya kepada penebusan Yesus dan kebaikan Allah sebagaimana ditekankan dalam ibadah kebangunan rohani tersebut. Sudah satu tahun lebih sesudah nazar itu diucapkan namun tidak terjadi kesembuhan apa pun di dalam dirinya. Akhirnya, ia kecewa dengan teologi dari tim visitasi dan gereja tempat ia didoakan.

Dari narasi di atas, ada dua hal yang akan didiskusikan dalam tulisan ini yaitu: pertama, “Bagaimana menganalisa teologi Pentakostal di atas tentang hubungan

$5 \quad$ Ian Andrews, Equipped to Heal Columbus (GA: TEC, 2003), 17. Dikutip dalam Jörg Stolz, "All Things Are Possible: Towards a Sociological Explanation of Pentecostal Miracles and Healings," dalam Sociology of Religion no: 72:2 (April: 2011): 458. 
antara doktrin penebusan dan kesembuhan?" Kedua adalah "Bagaimana hubungan antara doktrin kesembuhan dengan kebaikan Allah?”

Tulisan ini mencoba untuk merekonstruksi teologi Pentakostal tentang kesembuhan, dari tim visitasi dan gereja itu. ${ }^{6}$ Oleh karena mereka berasal dari tradisi gereja yang beraliran Pentakostal maka tulisan ini akan menelusuri konsep mengenai mujizat kesembuhan dari teologi Pentakostal. Begitu banyak tokoh Pentakosta yang memiliki teologi tentang mujizat kesembuhan. Penulis hanya memaparkan tokohtokoh dan pandangan mereka yang dinilai telah menjadi dasar atau mempunyai kaitannya dengan pemahaman teologis dari tim visitasi dan gereja tersebut. Untuk membatasi pembahasan soal mujizat kesembuhan, maka tulisan

ini tidak akan masuk dalam telaah dari perspektif psikologi ${ }^{7}$, antropologi (dengan istilah risetnya disebut the Placebo effets ${ }^{8}$ ), dan sosiologi. ${ }^{9}$

\section{DOKTRIN KESEMBUHAN DARI TEOLOGI PENTAKOSTAL}

Gereja Pentakosta percaya bahwa kesembuhan ilahi dapat dimungkinkan terjadi karena Yesus telah menderita di atas kayu salib bagi manusia yang berdosa. Pengorbanan Yesus di atas kayu salib,

". . . can heal any illness whatsoever, be it a small ailment (e.g., a headache), a mental problem (such as depression), or very serious physical maladies (e.g., cancer, AIDS). It follows that healing is never just physical, but by definition physical, mental, and spiritual simultaneously."10

6 Pengakuan Iman dari Tim visitasi dan Gereja itu seperti tertulis dalam "Majelis Pusat Harian Sinode GIA, Tata Gereja (Semarang: Sinode Gereja Isa Almasih, 2008), 6." Bagian ayat tertentu berkaitan dengan kesembuhan berbunyi sebagai berikut: "Aku percaya bahwa kesembuhan Ilahi berdasarkan bilur-bilur dan pengorbanan Kristus di kayu salib" (Yes. 53:5; Mat. 8:17; I Pet. 2:24; Yak. 5:14-15).

7 Misalnya kesembuhan dijelaskan sebagai sebuah proses psykosomatik. Proses ini mau mengatakan bahwa faktor psikologis mempunyai peranan penting dalam kesembuhan atas suatu penyakit.

8 Lihat Jörg Stolz, "All Things Are Possible: Towards a Sociological Explanation of Pentecostal Miracles and Healings," dalam Sociology of Religion no: 72:2 (April: 2011): 458. Ia menjelaskan pandangan para antropolog yang mengatakan, " . . the placebo effect shows that humans are a socio-psychophysical entity in which the symbolic may have an effect on the physical..."

9 Stolz juga menjelaskan yang dimaksud dengan perspektif sosiologi adalah mencari penjelasan dari sisi netral atau obyektif berkaitan dengan penyembuhan dan mujizat. Penyembuhan dan mujizat tidak dilihat baik secara positif maupun ditolak sebagaimana dilakukan para kritikus yang skeptis. Para ahli sosiologi mengamati dan melaporkan apa-apa yang terjadi dalam peristiwa kesembuhan dan mujizat sebagaimana apa adanya. Lihat Stolz, "All Things Are Possible," 458. 
Gereja Pentakosta juga percaya bahwa mujizat tetap terjadi sampai sekarang ini karena Allah masih terus bekerja menyatakan perbuatan-Nya yang ajaib yang melampaui kemampuan manusia dan hukum alam. Mujizat adalah karya supranatural Allah yang mengintervensi di dalam kehidupan manusia sehari-hari. Mujizat terjadi di dalam dunia ini dan di dalam kehidupan orangorang percaya untuk membuktikan tentang kemahakuasaan Allah dan itu juga menyatakan bahwa Yesus adalah Tuhan.

Selanjutnya sebelum menguraikan doktrin mujizat kesembuhan dari teologi Pentakostal maka perlu dipahami terlebih dulu pengajaran Pentakosta mengenai Full Gospel, yang berpusat kepada pribadi Yesus sebagai juru selamat(savior), penyembuh(healer), pembaptis (baptizer) dengan Roh Kudus, dan kedatanganNya untuk yang kedua kali dalam waktu dekat (soon coming King). ${ }^{11}$ Pengaruh gerakan kekudusan di abad ke-19 menambahkan Yesus sebagai Pengudus (sanctifier) dalam pengakuan beberapa aliran Gereja-Gereja Pentakosta, khususnya di Amerika. Gereja-Gereja Pentakosta di konteks zaman sekarang ini menambahkan pengajaran mereka tentang Full Gospel yaitu mengenai Yesus pemberi berkat materi (teologi kemakmuran). ${ }^{12}$

Allan Anderson mengatakan bahwa dalam konsep Full Gospel pengajaran Yesus sebagai Juru Selamat (Savior) atau Penebus (Redeemer) dikaitkan secara doktrinal dengan Yesus sebagai Penyembuh (Healer). Yesus tidak saja menyelamatkan manusia dari dosa tetapi Dia juga penyembuh dari sakit penyakit dan melepaskan dari kuasa setan. ${ }^{13}$ Teks-teks yang melandasi pengajaran tersebut seperti di Yesaya 53:4-5, Matius 8:16-17, dan I Petrus 2:24. Bukan jiwa saja yang ditebus tetapi tubuh juga ditebus dengan berkat kesehatan di dalamnya. ${ }^{14}$ Jonathan R. Baer mengatakan:

11 Bnd. Donald W. Dayton, "Theological Roots of Pentecostalism," dalam Pneuma: the Journal of the Society for Pentecostal Studies (Spring, 1980):4. Jesus saves us according to John 3:16. He baptizes us with the Holy Spirit according to Acts 2:4. He heals our bodies according to James 5:15-15. And Jesus is coming again to receive us unto Himself according to I Thessalonians 4:16-17."

12 Lihat contohnya perkembangan Gereja Pentakostal di Korea Selatan, terutama dalam kasus Yoido Full Gospel Church yang dipimpin oleh Paul Yonggi Cho. Selain aspek Full Gospel, Cho juga menekankan Injil kemakmuran. Lihat Paul Yonggi Cho, Dimensi Keempat: Lebih Banyak Rahasia untuk Kehidupan Iman yang Berhasil, terjemahan Wimanjaya K. Liotohe, ed. ke-2 (Jakarta: Yayasan Pekabaran Injil Immanuel, 1986), 15. Bandingkan dengan Dongsoo Kim, "The Healing of Han in Korean Pentecostalism," dalam JPT 15 (1999): 123-139. Seorang Teolog Pentakosta bernama Allan Anderson, tampaknya tidak setuju menyebut tokoh-tokoh seperti Essek W. Kenyon, Oral Robert, Kenneth Hagin, Norman Vincent Peale, Yonggi Cho masuk dalam aliran Pentakostal. Hal tersebut oleh karena penekanan Injil kemakmuran bukan menjadi bagian dalam teologi Pentakostal klasik di Amerika Utara. Namun demikian Anderson mengatakan bahwa di benua Asia, Afrika, dan Amerika Latin perkembangan aliran Pentakostal, Karismatik, dan Pentakostal Baru (New Pentakostal) bercampur baur termasuknya di dalamnya bersama-sama menekankan soal Injil kemakmuran(selain penekanan doktrin Full Gospel).

13 Allan Anderson, "Pentecostal Approaches to Faith and Healing," dalam Review of Mission 91 (2002): 524.

14 Anderson, "Pentecostal Approaches,"524. 
"Pentecostalism originated in the body as much as the spirit. The 'Full Gospel' it proclaimed promised renewed health along with saved souls, and its embryonic ethos prized the human embodiment of divine initiative." 15

Aliran Pentakostal menekankan bahwa Full Gospel berbicara mengenai keselamatan holistik yang mencakup semua penyelesaian problem kehidupan manusia, termasuk di dalamnya kesembuhan dari penyakit. "Healings demonstrated Christ's victory over all forms of affliction; it was a holistic salvation that encompassed all of life's problem." 16 Anderson menambahkan bahwa salvation juga kadang-kadang disebut Full Salvation yang berarti

" . . . a sense of wellbeing evidenced in freedom from sickness, poverty, and misfortune, as well as in deliverance from sin and evil. Healing from sickness and deliverance from evil powers are seen as part of the essence of the Gospel, reference being made to Old prophets, Christ himself and New Testament apostles who practised healing. "17

Selain penekanan di atas, aliran Pentakostal menghubungkan doktrin kesembuhan dengan didasari pada pengajaran tentang Allah itu baik. ${ }^{18}$ Tokohtokoh Pentakosta di masa lalu seperti Herman Zaiss, Oral Roberts, A.A. Allen menekankan, apa yang dikategorikan oleh Walter J. Hollenweger, tentang "God is a Good God: The Fight against Illness. "19 Kebaikan Allah disandingkan dengan kemahakuasaan-Nya yang mampu memberikan kuasa kesembuhan melalui karya Roh Kudus. Anderson membenarkan pernyataan di atas ini dengan mengatakan:

Pentecostals believe in omnipotent and compassionate God who is concerned with all human troubles and willing to intervene to alleviate them ... Reinforced by the power of the Spirit, they announce the good news of deliverance from sin, sickness, and oppression, and from every conceivable

\footnotetext{
15 Jonathan R. Baer, "Redeemed Bodies: The Functions of Divine Healing in Incipient Pentecostalism," dalam The American Society of Church History Church History, no. 70:4 (December 2001):735.

16 William W. Menzies dan Robert P. Menzies, Spirit and Power:Foundations of Penecostal Experience (Grand Rapids: Zondervan, 2000), 168. Bandingkan John Wimber dan Kevin Springer, Power Healing (New York: Harper Collins, 1991), 37.

17 Anderson, "Pentecostal Approaches," 526.

18 Walter J. Hollenweger, The Pentacostals (Peabody, Massachusetts: Hendrickson Publishers, 1972), 362-367.

19 Hollenweger, The Pentacostals, 362-367.
} 
form of evil, including social deprivation, unemployment, poverty and sorcery. The emphasis on experiencing the power of the Spirit is a common characteristic of Pentecostal theology, where the Holy Spirit is the agent of healing and deliverance. ${ }^{20}$

Oral Robert dalam khotbah-khotbah tentang kesembuhan menekankan tentang hasrat Allah untuk menyatakan kebaikan-kebaikan-Nya melalui menyembuhkan atau membawa wholeness kepada orang-orang. ${ }^{21}$ Ia juga mengatakan,

"God is a good God, and the devil is a bad devil. God's will for you is good (health, riches, well-being); The devil's will for you is bad (sickness, poverty, depressions). Therefore make your choice for the good, for God!"22

Tim visitasi dan gereja yang melayani Tirto mempunyai keyakinan tentang tersedianya mujizat kesembuhan sampai sekarang ini didasari oleh doktrindoktrin di atas tersebut. Pertanyaan kritisnya, "Mengapa kesembuhan tidak terjadi di dalam diri Tirto?" Bukankah ia sudah lama percaya kepada Yesus sebagai juru selamat dan penebus? Sebagai orang Kristen, ia juga percaya tentang kebaikan Allah. Ia tidak pernah ragu-ragu mengenai hal-hal tersebut. Bagaimana merekonstruksi teologi Pentakostal yang telah dipaparkan di atas tersebut? Teologi yang telah menyebabkan kekecewaan, kesedihan, bahkan penderitaan batin bagi diri Tirto ini? Konstruksi teologi yang baru yang bagaimanakah yang dapat dimunculkan berkaitan dengan kehidupan Tirto? Sebuah konstruksi teologi yang baru perlu dimunculkan dengan harapan mungkin dapat menolong pergumulan yang dihadapi oleh Tirto - mungkin juga “Tirto-Tirto" lainnya - dalam konteks teologi kesembuhan Pentakosta?

Anderson, "Pentecostal Approaches,"527.

Anderson, "Pentecostal Approaches,"527.

Hollenweger,The Pentacostals, 363. 


\section{REKONSTRUKSI TEOLOGI KESEMBUHAN PENTAKOSTAL}

Metode berteologi yang dipakai untuk mengkonstruksi teologi Pentakostal di atas diambil dari perspektif renewal theology yang berfokus pada pneumatologis. ${ }^{23}$ Rekonstruksi teologi ini membahas tentang hubungan antara penebusan Yesus, kebaikan Allah, dan kesembuhan.

Di dalam teologi sistematika ada banyak penjelasan tentang arti penebusan Yesus. Seorang teolog Protestan yang bernama B.B. Warfield, sebagaimana dikatakan oleh Leanne Van Dyk memaparkan berbagai teori yang cukup lengkap mengenai penebusan Yesus dan dampak-dampak dari penebusan tersebut sebagai berikut ${ }^{24}$ : pertama, berdampak kepada setan karena kematian Yesus mengalahkan kuasa setan. Teori ini diikuti oleh Augustinus, Gregrory the Great, dan masih muncul di abad pertengahan dan masa Reformasi. Kedua, berdampak kepada manusia secara fisik dalam arti manusia yang diselamatkan berpartisipasi dalam kehidupan Kristus. Teori ini diikuti oleh aliran mistik Kristen, PseudoDionysius dan orang-orang yang dipengaruhinya seperti Schleiermacher, the Mercersburg School, dan F.D. Maurice. Ketiga, berdampak kepada manusia sehingga manusia mempunyai tindakan etis yang benar. Teori ini diikuti oleh Ritschl, Herrmann, Bushnell, dan para teolog Injil Sosial. Keempat, berdampak secara utama kepada manusia dan selanjutnya kepada Allah. Penebusan Kristus menyebabkan manusia bertobat dan beriman, Allah kemudian mengampuni mereka. Teori ini diikuti oleh Grotius, Armenian, para pengikut Jonathan Edward di abad 18, dan kelompok Methodis. Kelima, berdampak secara utama kepada Allah dan kemudian kepada manusia yang ditebus. Karya Yesus di atas kayu salib menyatakan kasih Allah melalui mempersembahkan hidup Yesus kepada-Nya. Hasilnya, Allah di dalam dan melalui Yesus memberikan anugerah keselamatan

$23 \quad$ Teologi ini muncul karena adanya kebangkitan pemahaman yang baru tentang Pribadi dan karya Roh Kudus sebagai dasar untuk berteologi secara luas dan kontekstual. James K.A. Smith dalam bukunya berjudul Thinking in Tongues menggunakan sebutan "pentakostal" (huruf " $\mathrm{p}$ " kecil) sebagai istilah untuk metode berteologi yang baru itu bagi seluruh Gereja atau teologi Kristen. Ini bukan metode berteologi dari denominasi Pentakosta dan Karismatik saja. Melalui metode berteologi pentakostal ini isu-isu dari kehidupan ini dicoba dikaji, dianalisa, dan direfleksi dari terang perspektif pneumatologis. Menurut Smith, metode berteologi pentakostal adalah sebuah cara untuk mendapatkan pengertian iman Kristen secara radikal melalui membuka diri secara spiritual dan akademis terhadap karya-karya Roh Kudus yang berkelanjutan sampai dengan sekarang ini. Lihat James K.A. Smith, Thinking in Tongues: Pentecostal Contributions to Christian Philosophy (Grand Rapids, Michigan: William B. Eerdmans Publishing Company, 2010), 7.

24 Leanne Van Dyk, "John Mcleod Campbell's Doctrine Of The Atonement: A Revision And Expansion Of The Reformed Tradition" (disertasi Ph.D, Princeton Theological Seminary, 1992), 109 - 112. 
kepada manusia. Penebusan yang dinyatakan Yesus mempermuliakan Allah dan berakibat manusia diselamatkan. Teori ini diikuti oleh Turretin, para Skolastik Protestan, John Owen, Abraham Kuyper, and Charles Hodge.

Dalam kalangan Protestan ada perdebatan mengenai teori mana yang paling penting dari teori lainnya. ${ }^{25}$ Dengan tidak mengabaikan bagian-bagian lainnya, tampaknya poin kelima menempati posisi sentral untuk mengartikan karya penebusan Yesus. Hal tersebut dikarenakan keyakinan teologis pada poin kelima didasari oleh beberapa teks sentral di dalam kitab suci seperti Yohanes 3:16; Matius 20:28; Markus 10:45; Roma 3:24; Efesus 1:7,14 ; Titus 2:13; Ibrani 1:3, 2:9; I Petrus 1:11; Wahyu 5:12 ). Sebaliknya dapat dikatakan bahwa tidak ada perdebatan di dalam teologi Pentakostal mengenai poin-poin mana di atas yang paling sentral. Namun poin-poin di atas yang berkaitan dengan teologi kesembuhan Pentakosta adalah di poin pertama dan kedua. Dalam pengalaman kesembuhan Pentakostal ada banyak kasus kesembuhan yang dihubungkan dengan pengertian penebusan dari poin pertama, yaitu sakit penyakit dari kuasa setan dan saat kuasa itu dikalahkan oleh kuasa Roh Kudus maka kesembuhan terjadi. ${ }^{26}$ Meskipun demikian perlu diberi catatan bahwa teologi Pentakostal masa kini tidak melihat semua sumber sakit penyakit dan penderitaan berasal dari kuasa setan. ${ }^{27}$ Teologi kesembuhan Pentakostal juga dikaitkan dengan poin kedua, yakni dampak penebusan Yesus berhubungan dengan berkat kesembuhan fisik (kesehatan) dan berkat materi. Jika seseorang menerima berkat-berkat ini maka artinya berpartisipasi dalam kehidupan Kristus yang riil menurut teologi Pentakostal. Menurut saya, kontribusi teologi Pentakostal adalah menghubungkan berkat kesembuhan dan berkat materi dengan doktrin penebusan. Bukankah berkat-berkat Abraham juga diberikan kepada orangorang yang mengalami penebusan Yesus (Gal. 3:8,9,14)?

25 Lihat Dyk, “John Mcleod Campbell's Doctrine," 109-112; Alister E. McGrath, Christian Theology: An Introduction (Massachusetts, USA: Blackwell Publishers, 1997),390-411. Dalam bukunya itu McGrath hanya menyebutkan teori penebusan Kristus dalam empat kategori yaitu "The cross as a sacrifice; the cross as a victory; the cross and forgiveness; and the cross as a moral example." Bnd. Millard J. Erickson, "The Atonement," dalam Millard J. Erickson peny., Readings in Christian Theology, vol. 2 (Grand Rapids, Michigan:Baker Book House, 1992), 351-358.

26 Peter L. Berger mengobservasi pandangan dunia (worldview) teologi Pentakostal dengan mengatakan, "The spiritual world is close at hand. The empirical world is constantly penetrated by spiritual beings both good and evil: the Holy Spirit and the angels, demons and even Satan himself. What is more, human beings who have been baptized in the Holy Spirit may acquire the "gifts of the Spirit" (the charismata of the New Testament), including the laying on of hands to heal the sick, exorcism of demons, prophecy, and even, on occasion, the raising of the dead. Lihat Peter L. Berger, "Friendly Dissent from Pentecostalism," dalam First Things (November 2012): 47.

Hollenweger, The Pentacostals, 363-370. 
Apakah yang menyebabkan teologi Pentakostal memasukkan kesembuhan fisik dalam kaitannya dengan doktrin penebusan? Pertama, teologi Pentakostal menekankan hubungan penebusan Yesus dan kesembuhan sebagaimana dicatat di teks-teks Yesaya 53:4-5, Matius 8:16-17, dan I Petrus 2:24. Penafsiran teologi Pentakostal secara literal terhadap teks-teks tersebut menyebabkan pemahaman tentang kesembuhan dikaitkan dengan hal-hal secara fisik. Teologi Pentakostal juga memahami teologi kesembuhan dari teks-teks tersebut terpisah dari konsep teologi lainnya seperti teologi penderitaan. Oleh karena penekanan kepada berkat fisik dan materi maka pembicaraan tentang penderitaan tidak menjadi agenda teologinya. Jika membicarakan penderitaan Yesus maka selalu dikunci dengan topik-topik teologi kebangkitan Yesus yang menang atas penderitaan.

Kedua, teologi Pentakostal menekankan Yesus sebagai Pembaptis dengan Roh Kudus. Ia mengutus Roh Kudus yang akan memberi kuasa kepada orang-orang percaya (Kis. 1:8). Teologi tentang Roh Kudus yang memberi kuasa kepada orangorang percaya menjadi sentral dalam teologi Pentakostal. Sejak muncul dalam sejarah gereja hingga sekarang ini, Gereja Pentakosta menekankan bahwa kuasa Roh Kudus diberikan melalui karunia-karunia rohani seperti karunia bahasa roh (glosolali), karunia menafsirkan bahasa roh, karunia kesembuhan, karunia pengusiran setan, karunia nubuat, dan sebagainya. ${ }^{28}$ Karunia-karunia itu masih tetap diberikan oleh Allah melalui karya Roh Kudus hingga di zaman sekarang ini. Jika gereja menghadirkan kesembuhan dan mujizat lainnya maka ini bukti bahwa kuasa Roh Kudus terus berkarya di zaman sekarang ini. ${ }^{29}$ Pelayanan mujizat kesembuhan merupakan salah satu faktor yang sangat penting dalam mendorong pertumbuhan dan perkembangan Gereja-Gereja Pentakosta. ${ }^{30}$ Tanpa kuasa kesembuhan, pelayanan Kristen hanyalah berisi kata-kata dan perbuatan-perbuatan manusia saja yang terbatas dan tidak punya daya kuasa ilahi di dalamnya. Seorang peneliti sosial bernama Peter L. Berger mengatakan,

"For Pentecostals, miracles, especially miracles of healing, are very real." 31

28 Bnd. dengan Para Teolog-Teolog Injil Amerika, "American Evangelical theologians (very non-Pentecostal ones) have developed a doctrine called "cessationism": Miracles have ceased because they are no longer needed, either after Jesus' earthly ministry came to an end or after the canon of the New Testament was completed. Mainline Protestants, I think, just prefer not to think about such matters too much." Peter L. Berger, "Friendly Dissent," 47.

29 Bnd. G. Jeffrey, "The Gospel of the Miraculous," dalam D. Gee ed., The Phenomena of Pentecost (Springfield, Mo.: GPH, 1931), 50.

30 Hollenweger, The Pentacostals, 353-373 dan Kim, "The Healing of Han,"123-139.

31 Berger, "Friendly Dissent," 46-47. 
Apa yang dapat kita kritisi dari teologi kesembuhan Pentakostal? Catatan kritis pertama untuk mengkritik teologi Pentakostal adalah generalisasi teks-teks tertentu di dalam teologi Pentakostal untuk menekankan mujizat kesembuhan. Teks-teks teologi kesembuhan Pentakostal tidak terbuka dan didialogkan dengan teks-teks lain di kitab suci yang berbicara tentang beberapa orang-orang percaya yang tidak mengalami kesembuhan dan kelepasan dari penderitaan (perhatikan kasus penderitaan Paulus yang dicatat dalam II Kor. 12:7; bnd. penderitaan orang-orang percaya Ibrani 11:37;bnd. Fil. 1:29; Kol. 1:24; I Pet. 2:20-21; I Pet. 4:1, 16, 19, I Pet. 5:10).

Catatan kritis kedua, pengajaran kuasa Roh Kudus berkaitan kesembuhan bukan berarti itu salah karena kitab suci sendiri banyak bercerita mengenai mujizat kesembuhan yang dikerjakan oleh Roh Kudus. Apalagi menurut sejarah misi Pentakostal telah terbukti bahwa pelayanan kesembuhan Ilahi telah banyak membawa orang-orang kepada Kristus. Banyak kasus mujizat kesembuhan terjadi saat pemberitaan Injil seperti di wilayah Lake Afrika Selatan, Burtonin Congo, Berg and Cook di India, beberapa wilayah di Afrika, Asia, dan Mesir. Namun yang sering dilupakan oleh teologi Pentakostal adalah adanya laporanlaporan tentang cerita mujizat kesembuhan yang tidak terjadi di medan pekabaran Injil. Seperti contohnya para missionaris dari gerakan Pentakostal awal yang meninggal karena penyakit diare, cacar, malaria, dan TBC seperti yang terjadi di Hongkong 1910, Liberia 1907, Shanghai 1910, dan 1915. ${ }^{32}$

Dalam konteks modern, menurut Anderson pelayanan kesembuhan tidak terjadi di setiap tempat tetapi,

"... particularly relevant in those societies where disease is rife and access to adequate health care is a luxury." ${ }^{\prime 33}$

Lebih lanjut, ia menceritakan pelayanan Claudia Wワhrish-Oblau di Cina dengan mengatakan,

". . . the need for healings is in direct proportion to the unavailability of medical resources and the breakdown of the public health system there. "34

32 Allan Anderson, Spreading Fires: The Missionary Nature of Early Pentacostalism (London: SCM Press, 2007), 215-219.

33 Anderson, "Pentecostal Approaches,"526.

34 Anderson, "Pentecostal Approaches,"526. 
Tambahan, mengutip pernyataan Oblau, Anderson mengatakan bahwa doa untuk kesembuhan adalah

"an act of desperation in circumstances where they see few alternative

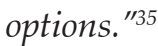

Dalam kasus Tirto, teologi kesembuhan dari tim visitasi dan gereja itu tidak operatif baginya atau menjawab kebutuhannya. Dengan tidak terjadinya kesembuhan maka teologi mereka menimbulkan pergumulan batin bagi Tirto. Lalu bagaimana mengembangkan suatu teologi Pentakostal dari perspektif renewal theology yang memerhatikan pergumulan Tirto ini?

Kecenderungan teologi Pentakostal adalah menggambarkan Roh Kudus di dalam satu arah saja, yaitu penekanannya terhadap kebaikan, keberkatan, pemeliharaan, kenyamanan, dan kebebasan dari kesukaran, dan kesembuhan. Menurut T. David Beck, pengajaran pneumatologis seperti ini cenderung terlalu ramah dan jinak yang pada akhirnya dapat memunculkan karikatur tentang pribadi Roh Kudus. Roh Kudus menjadi a vanilla third Person. Beck mengatakan hal ini sebagai berikut:

". . . a 'vanilla' third Person-a caricature in which the Spirit becomes overly friendly and benign. The danger is that the Comforter can become too comfortable. ${ }^{36}$

Teologi ini menurutnya menekankan pneumatologi dari Barat (Western pneumatology) yang cenderung kepada teologi kemuliaan (theology of glory) daripada teologi salib (theology of the cross). ${ }^{37}$

Untuk merekonstruksi teologi Pentakostal dari tim visitasi dan gereja itu, saya meminjam istilah yang dipakai oleh Beck yaitu tentang transformative

$35 \quad$ Claudia W $\square$ hrish Oblau, "God Can Make us Healthy Through and Through: On Prayers for the Sick and Healing Experiences in Chrstian Churches in China and African Immigrant Congregrations in German," dalam International Review of Mission, XC:356/357 (January/April 2001): 94, 99.

36 T. David Beck, "The Divine Dis-Comforter: The Holy Spirit's Role in Transformative Suffering," dalam Journal of Spiritual Formation \& Soul Care vol. 2 no. 2 (2009): 200.

37 Beck, "The Divine Dis-Comforter,"200. Bandingkan Choan-Seng Song, Allah yang Turut Menderita, terjemahan Stephen Soleeman (Jakarta: BPK Gunung Mulia, 1993); Kosuke Koyama, "Allah yang berkecepatan Tiga Mil Per Jam," dalam Douglas J. Elwood peny., Teologi Kristen Asia, terjemahan B.A.Abednego (Jakarta: BPK Gunung Mulia, 1993), 98-104. 
suffering..$^{38}$ Roh Kudus sebagai the agent of transformative suffering bagi orangorang percaya yang sedang dalam sakit penyakit dan penderitaan. Apa artinya teologi ini? Teologi ini mengajar bahwa Roh Kudus tidak meninggalkan orangorang percaya dalam situasi pahit. Dia mampu mentransformasi kehidupan orang-orang percaya tersebut agar mereka dapat menghayati dan memaknai penderitaan mereka dalam terang kasih Allah. Pandangan umum teologi Kristen mengatakan bahwa di tengah-tengah dunia yang tidak sempurna dan telah jatuh ke dalam dosa berakibat penderitaan muncul. Seorang Rabi Yahudi mengatakan—kira-kira demikian—bahwa kita dapat berharap semoga pelbagai hal bisa menjadi lebih baik, namun kita perlu bersiap-siap juga apabila semua menjadi tidak baik atau buruk. Jikalau penderitaan tidak dapat terhindarkan dari kehidupan Kristen maka mungkin itu dapat menjadi salah satu cara untuk menumbuhkan kedewasaan iman Kristen (Yak. 1:2-4). Kuasa Roh Kudus tetap dinyatakan di dalam diri orang-orang percaya yang telah berdoa dan beriman untuk kesembuhan penyakit mereka meski tidak ada jawaban untuk kesembuhan tersebut. Roh Kudus berjanji untuk menyertai dan memberi kekuatan kepada mereka dan tetap dengan setia menopang mereka (Yoh. 14:26, 15:26, 16:17; Kis. 9:31; bnd. Rm. 8:26-28).

Lebih lanjut, Roh Kudus sebagai the agent of transformative suffering mengajarkan kepada kita bahwa penderitaan yang terjadi di dalam diri orangorang percaya karena Allah mengijinkan itu terjadi. Pernyataan ini tidak dimaksudkan untuk menyepelekan situasi kongkret orang-orang yang sedang mengalami penderitaan. Rasul Paulus mengalami penderitaan oleh karena Allah mengijinkan itu terjadi (2 Kor. 12:7-10). Dalam penderitaannya, Paulus semakin beriman dan memahami begitu besar dan dalam kasih karunia Allah di dalam hidupnya. Penderitaannya membawa dia dalam proses pengudusan untuk semakin mengenal pribadi Kristus (2 Kor.12:9). Bagi Paulus penderitaannya menyatakan kebaikan dan kemuliaan Allah. Di taman Getsemani, Yesus mengalami pergumulan yang hebat antara mengikuti kehendak manusiawiNya atau kehendak Ilahi-Nya, tetapi pada akhirnya Ia memutuskan memilih

$38 \quad$ Beck menggunakan istilah ini untuk menggambarkan peranan Roh Kudus yang tidak sekedar memberikan hal-hal yang baik, tetapi ada peranan Roh Kudus yang membawa orang percaya masuk dalam penderitaan yang mentransformasi. Ia mencontohkan pemikiran teologi ini melalui mengeksegesis Markus 1:12 dan teologi John the Cross. Dalam tulisan yang terbatas ini, saya tidak akan menjelaskan artikel yang ditulis oleh Beck tersebut. Saya hanya mencoba menarik teologi dan implikasi pemikiran Beck ini untuk merekonstruksi proyek teologi yang saya tulis di paper ini. 
untuk mengikuti kehendak Bapa menjalani peristiwa salib. Ia menderita tetapi penderitaan-Nya membawa transformasi keselamatan bagi dunia ini.

Ketika kesembuhan tidak terjadi bukan berarti kebaikan Allah tidak ada di dalam diri orang-orang percaya yang mengalami sakit penyakit dan penderitaan. Juga tidak berarti pula bahwa Allah tidak berkuasa melakukan kesembuhan. Kekeliruan teologi Pentakostal adalah sering mengklaim mengenai kemahakuasaan Allah atau "tidak ada yang mustahil bagi Allah" dalam doadoa mereka agar kesembuhan terjadi. Berdoa meminta kesembuhan dengan memanjatkan doa "biarlah kehendak Allah saja yang terjadi" jarang mereka ucapkan karena keyakinan konsep kuasa Roh Kudus yang mereka pahami. Konsep teologi Pentakostal ini justru menunjukkan suatu pengajaran yang cukup berbahaya karena menempatkan kesembuhan sebagai hal yang paling utama dan terlebih-lebih lagi tampaknya teologi ini menunjukkan adanya keinginan untuk terjadinya kesembuhan sebagai sesuatu yang tidak terelakkan. Bukankah ini dapat membawa kepada penekanan kehendak manusia? Bukankah semestinya doa yang berisi pernyataan "tidak ada yang mustahil bagi Allah" mesti disertai dengan doa "biarlah kehendak Allah saja yang terjadi?"

Selanjutnya, perlu dicatat bahwa bukan melakukan kesembuhan dan mujizat yang paling utama yang Yesus kerjakan. Memang tidak dapat dipungkiri bahwa Yesus sebagai penyembuh begitu menonjol diceritakan dalam Injil. Kisah-kisah mujizat kesembuhan yang dilakukan-Nya begitu beragam misalnya penyembuhan terhadap orang sakit kusta (Mat. 8:1-4, 9:1-8 bnd. Mrk. 1:40-45, 2:1-12; Luk. 5:12-16, 5:17-26); penyembuhan terhadap orang lumpuh (Mat. 8:5-13 bnd. Luk. 7:1-10; Yoh. 4:46-53); penyembuhan kepada orang kerasukan setan (Mat. 8:28-34, bnd. Mrk. 5:1-20; Luk. 8:26-39); penyembuhan kepada perempuan yang sakit pendarahan (Mat. 9:19-22, bnd. Mrk. 5:21-43; Luk. 8:40-56); penyembuhan kepada orang buta dan bisu (Mat. 9:27-34, 15:29-29-31. Juga lihat Mat. 20:2934, bnd. Mrk. 10:46-52; Luk. 18:35-43); penyembuhan kepada orang yang mati sebelah tangannya (Mat. 12:9-15, bnd. Mrk. 3:1-6; Luk. 6:6-11); penyembuhan kepada seorang anak muda yang sakit ayan (Mat. 17:14-18, bnd. Mrk. 9:14-29; Luk. 9:37-43). Tetapi pertanyaan yang penting adalah adalah, "Apakah tujuan mujizat-mujizat kesembuhan yang dilakukan oleh-Nya tersebut?"

Teologi Injil Yohanes menyatakan tentang lebih pentingnya memerhatikan prioritas utama karya Roh Kudus sebagai Pribadi yang memberikan kelahiran baru kepada manusia daripada hanya sebatas menyatakan tanda-tanda keajaiban 
(termasuk kesembuhan). Dalam kisah perjumpaan Yesus dengan Nikodemus dalam Yohanes 3:1-21 diceritakan tentang kekaguman Nikodemus terhadap tanda-tanda yang diadakan Yesus (Yoh. 3:2). Alih-alih meresponi keheranan Nikodemus terhadap keajaiban dan tanda-tanda yang ada, Yesus menyampaikan hal yang jauh lebih penting tentang pekerjaan Roh Kudus, yaitu Roh Kudus sebagai pemberi kelahiran baru. Yesus menekankan penting pembaruan hidup atau kelahiran baru sebagai syarat utama masuk dalam Kerajaan Allah. Dalam kata lain, bisa saja mujizat kesembuhan tidak terjadi bagi orang-orang percaya meski telah lama berdoa dan beriman ataupun telah bernazar. Jika kesembuhan tidak terjadi tidaklah menjadi soal, namun yang penting adalah mereka mengalami pembaruan hidup atau kelahiran baru dalam diri mereka.

Dalam sakit penyakit dan penderitaan yang berat, karya Roh Kudus sebagai the agen of transformative suffering tidak terlepas dari karya-Nya sebagai the agent of the transformative life. Roh Kudus sebagai the agent of transformative suffering dapat memakai sakit penyakit dan penderitaan yang dialami oleh orangorang percaya untuk menyatakan karya pembaruan-Nya, yaitu kelahiran baru. Kelahiran baru disini diartikan sebagai transformasi Roh Kudus di dalam hidup mereka sehingga kehidupan mereka sungguh-sungguh dapat menyatakan kehidupan yang sesuai dengan nilai-nilai Kerajaan Allah yang berisi sukacita, kesetiaan, kesabaran, kasih, kebenaran, damai sejahtera, dan sebagainya. Inilah karya Roh Kudus sebagai the agent of transformative life. Kebaikan Allah yang paling utama adalah manusia beroleh pengampunan dan anugerah-Nya; dan akibatnya manusia terlepas dari dosa-dosa mereka. Sesuatu yang lebih besar yang diinginkan oleh Roh Kudus di dalam diri manusia adalah terbebasnya manusia dari rasa bersalah dan dosa-dosa kepada Allah. Sekalipun mungkin kesembuhan tidak terjadi itu bukanlah soal, tetapi yang penting adalah terjadinya transformative suffering dan transformative life. Sebaliknya sekalipun kesembuhan itu terjadi, yang penting bukan kesembuhan itu sendiri tetapi pembebasan dari rasa bersalah dan dosa-dosa. Sebagaimana dikatakan oleh John Wimber and Kevin Springer mengatakan, "It is not the release from pain and sickness that is the primary goal of healing, it is the release from the guilt of sin." ${ }^{\prime \prime 3}$

39 Wimber with Springer, Power Healing,13. 


\section{PENUTUP}

Teologi Pentakosta membutuhkan perspektif pneumatologis yang baru yang mempercayai pribadi dan karya Roh Kudus sebagai the agent of transformative suffering dan the agent of transformative life. Saya berpendapat sumbangan renewal theology sangat berguna untuk memperbaiki kekeliruan konsep teologi kesembuhan Pentakostal. Pengajaran pribadi dan karya Roh kudus sebagai the agent of transformative suffering dan the agent of transformative life mesti mendapat porsi yang lebih diutamakan daripada sekadar menempatkan Roh Kudus sebagai agen kesembuhan. Mujizat kesembuhan tetap tersedia di zaman sekarang ini, namun demikian teologi tentang mujizat kesembuhan harus dibangun atas dasar pengajaran yang benar dan dapat dipertanggungjawabkan secara biblika. Mujizat tidak harus selalu dikaitkan dengan kesembuhan secara fisik dan berkat materi. Keberanian dan kesetiaan untuk tetap mengikut Yesus di tengah-tengah kesusahan dan penderitaan dapat juga disebut mujizat. Bahkan mujizat ada di dalam kehidupan sehari-hari kita sehingga kita dapat - sebagaimana dikatakan oleh Berger -, ". . . see every day as a miracle rather than miracles every day." ${ }^{\prime \prime 0}$

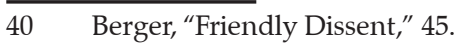




\section{DAFTAR PUSTAKA}

Anderson, Allan. Pentecostal Approaches to Faith and Healing, dalam Review of Mission 91 (2002)

Anderson, Allan Spreading Fires: The Missionary Nature of Early Pentacostalism (London: SCM Press, 2007)

Andrews, Ian. Equipped to Heal Columbus. GA: TEC, 2003 Dikutip dalam Jörg Stolz, All Things Are Possible: Towards a Sociological Explanation of Pentecostal Miracles and Healings, dalam Sociology of Religion no: 72:2 (April: 2011)

Baer, Jonathan R. Redeemed Bodies: The Functions of Divine Healing in Incipient Pentecostalism, dalam The American Society of Church History Church History, no. 70:4 (December 2001)

Beck, T. David. The Divine Dis-Comforter: The Holy Spirit's Role in Transformative Suffering, dalam Journal of Spiritual Formation \& Soul Care vol. 2 no. 2 (2009)

Berger, Peter L. Friendly Dissent from Pentecostalism, dalam First Things .November 2012.

Cho, Paul Yonggi. Dimensi Keempat: Lebih Banyak Rahasia untuk Kehidupan Iman yang Berhasil, terjemahan Wimanjaya K. Liotohe, ed. ke-2 (Jakarta: Yayasan Pekabaran Injil Immanuel, 1986)

Dayton, Donald W. Theological Roots of Pentecostalism, dalam Pneuma: the Journal of the Society for Pentecostal Studies (Spring, 1980)

Dyk, Leanne Van. John Mcleod Campbell's Doctrine Of The Atonement: A Revision And Expansion Of The Reformed Tradition. Disertasi Ph.D, Princeton Theological Seminary, 1992.

Erickson, Millard J. The Atonement, dalam Millard J. Erickson peny., Readings in Christian Theology, vol. 2 . Grand Rapids, Michigan:Baker Book House, 1992.

GIA, Majelis Pusat Harian Sinode. Tata Gereja (Semarang: Sinode Gereja Isa Almasih, 2008)

Hollenweger, Walter J. The Pentacostals, Peabody, Massachusetts: Hendrickson Publishers, 1972.

Jeffrey,G. The Gospel of the Miraculous, dalam D. Gee ed., The Phenomena of Pentecost (Springfield, Mo.: GPH, 1931)

John Wimber dan Kevin Springer, Power Healing, New York: Harper Collins, 1991. 
Kim, Dongsoo. The Healing of Han in Korean Pentecostalism, dalam JPT 15 (1999)

Koyama, Kosuke. Allah yang berkecepatan Tiga Mil Per Jam, dalam Douglas J. Elwood peny., Teologi Kristen Asia, terjemahan B.A.Abednego (Jakarta: BPK Gunung Mulia, 1993)

McGrath, Alister E. Christian Theology: An Introduction .Massachusetts, USA: Blackwell Publishers, 1997.

Oblau, Claudia W $\square$ hrish. "God Can Make us Healthy Through and Through: On Prayers for the Sick and Healing Experiences in Chrstian Churches in China and African Immigrant Congregrations in German," dalam International Review of Mission, XC:356/357 (January/April 2001)

Smith, James K.A. Thinking in Tongues: Pentecostal Contributions to Christian Philosophy. Grand Rapids, Michigan: William B. Eerdmans Publishing Company, 2010.

Song, Choan-Seng. Allah yang Turut Menderita, terjemahan Stephen Soleeman (Jakarta: BPK Gunung Mulia, 1993)

Stolz, Jörg. All Things Are Possible: Towards a Sociological Explanation of Pentecostal Miracles and Healings, dalam Sociology of Religion no: 72:2 (April: 2011)

William W. Menzies dan Robert P. Menzies, Spirit and Power:Foundations of Penecostal Experience, Grand Rapids: Zondervan, 2000.

Lihat https://www.ataxia.org/pdf/SCA-Making_an_Informed_Choice_About_ Genetic_Testing.pdf diakses pada tanggal 10 Maret 2016. 